\title{
The Effect of Health-related Quality of Life (HRQOL) on Health Service Utilisation of a Chinese Population
}

\author{
Cindy L K Lam, FRCGP, FHKAM (Family Medicine)* \\ Associate Professor, Family Medicine Unit, \\ Department of Medicine, \\ The University of Hong Kong \\ Daniel Y T Fong, Ph D, \\ Research Assistant Professor, Clinical Trials Centre, \\ The University of Hong Kong \\ Ian J Lauder, Ph D \\ Associate Professor, Department of Statistics \\ The University of Hong Kong \\ Tai-Pong D Lam, FRACGP, FHKAM (Family Medicine) \\ Associate Professor, Family Medicine Unit, \\ Department of Medicine, \\ The University of Hong Kong
}

\footnotetext{
*Correspondence: Family Medicine Unit, $3^{\text {rd }}$ Floor, Ap Lei Chau Clinic, 161 Main Street, Ap Lei Chau, Hong Kong SAR.

Tel: (852) 2552 6021; Fax: (852) 2814 7475;

Email: clklam@hku.hk
} 
HRQOL and Service Utilisation

\title{
The Effect of Health-related Quality of Life (HRQOL) on Health Service Utilisation of a Chinese Population
}

\begin{abstract}
Objectives: To find out whether health-related quality of life (HRQOL) was an independent determinant of health service utilisation of a Chinese population and to determine whether the addition of HRQOL data to sociodemographic and morbidity factors could significantly increase the explanatory power of risk-adjustment models. Design and Setting: A cross-sectional random telephone survey of the general adult Chinese population in Hong Kong. Subjects: 2410 Chinese aged 18 to 88 years old, 52\% were females and 38\% had one or more chronic diseases. Outcome Measures and Data Analyses: Health service utilisation was measured by annual consultation, monthly consultation and hospitalisation rates. HRQOL was measured by the SF-36. Multivariate regressions were used to test the dependence of service utilisation rates on sociodemographic factors, chronic morbidity and the SF-36 scores. Structured multiphase regression analyses were used to determine the magnitude of the effect of the SF-36 scores, in addition to those of sociodemographic and chronic morbidity factors, on service utilisation. Results: Five of eight SF-36 scores were independent determinants of consultation rates. They doubled and tripled the percentages of variance explained for annual and monthly consultation rates, respectively. Role limitation by physical problems and bodily pain scores had a significant effect on hospitalisation rates. Conclusions: This was the first study showing a linear relationship between HRQOL and service utilisation on a Chinese population. It confirmed the clinical relevance of the SF-36 to a culture and health care system that is different from that of the United States where the instrument originated.
\end{abstract}

Key Words: Quality of life, SF-36, Service utilisation, Consultation rates, Chinese 


\section{Introduction}

Ageing of the world's population and an increase in the proportion of disease burden from chronic diseases have drawn more attention to the relationship between health and quality of life (Testa and Simonson 1996; Abbasi 1999). Many studies have shown that perceived health is an important independent determinant of health service utilisation for Western populations (Hulka and Wheat 1985; Hornbrook and Goodman 1995; Mulunpalo et al 1997; Nelson et al 1998). Hornbrook et al found that HRQOL predicted linearly the annual medical expenses for working adults and their dependants (Hornbrook and Goodman 1995). Nelson et al found that physical functioning and mental health were important predictors of both hospital and outpatient services for patients with chronic diseases (Nelson et al 1998). Perceived global health had a linear relationship with annual outpatient consultation rates of a working-age population in Finland (Mulunpalo et al 1997).

Although health-related quality of life (HRQOL) has been used widely as a health outcome measure in the West for more than two decades, it is a relatively new concept in Asia. While few people disagree with the importance of quality of life, many are still uncertain about the clinical significance of HRQOL data for patients in this region (Testa and Simonson 1996). There are very few data on the relationship between HRQOL and health service utilisation for populations in Asia. A study by Matsumura in Japan showed that subjects with SF-36 physical and mental summary scores below 40 were more likely to use outpatient and in-patient services than those who had scores over 50 (Matsumura 2000). However, Cheng et al failed to show a consistent correlation between health status and health care cost on a group of Chinese elderly in Hong Kong (Cheng et al 1997). This raised doubts on whether 
HRQOL, a concept of Western origin, had the same clinical significance for the Chinese whose culture and health care system are very different from those of the West. There were several limitations in the study by Cheng et al: First, the sample was highly selective; second, health status was measured by a single global question; and third, health care cost is not a valid measure of service utilisation in Hong Kong because people can choose any combination of expensive private and heavily subsidised public services.

The aim of this study was to determine the effect of HRQOL on health service utilisation for the Chinese adult population in Hong Kong. The first objective was to find out whether the SF-36 scores, a widely used measure of HRQOL, were independent determinants of outpatient medical consultation and hospitalisation rates. The results would provide evidence on the clinical significance and relevance of HRQOL for the Chinese. The second objective was to determine whether the addition of the SF-36 scores to sociodemographic and morbidity variables could significantly increase the proportion of variance in utilisation rates explained. The results will give information on the possible value of including HRQOL scores in medical_risk adjustment equations for the estimation of various health service needs. 


\section{Methods}

\section{Study Design and Setting}

The study was a cross-sectional random telephone survey of the general adult Chinese population in Hong Kong. Ninety-six percent of the population in Hong Kong are Chinese and $10 \%$ of them are 65 years or older (Census \& Statistics Department Hong Kong 1996). Over 99\% of the households in Hong Kong have one or more telephones and all local calls are free of charge.

Although most of the population are Chinese, Western medical services are the main source of health care since traditional Chinese medicine (TCM) practitioners were not formally registered until late 2000 and there is no in-patient traditional Chinese medical service in Hong Kong. A recent general population survey found that only $7 \%$ of the outpatient health services were provided by TCM practitioners including herbalist, acupuncturist and bone-setters (The Harvard Team 1999).

The population is ageing and chronic diseases are common. Our total health care expenditure has been rising much more rapidly than the gross national product over the last ten years. The Government provides $93 \%$ of hospital care and $20 \%$ of primary care, at nominal charges, for the population in Hong Kong. A consultant team from Harvard projected that our health care system would become nonsustainable by 2016, unless there was better use of public health care funds (The Harvard Team 1999). Information on the determinants of health service utilisation can help us allocate limited resources more rationally to meet people’s needs. 


\section{Sampling Method}

Household telephone numbers were selected randomly from the Chinese Residential Telephone Directories published by the Hongkong Telecom, which contained $90 \%$ of all Chinese residential telephone numbers in Hong Kong (Hongkong Telecom 1997). The region (1= Hong Kong and Islands, 2= Kowloon and 3=New Territories), page, column and row numbers of the Directories of each sampled telephone number were specified by a computer-generated random number table. Trained interviewers called the households in the order of the random telephone list in the evening of each weekday from June 1 to September 30, 1998. Among those members who were present in the contacted household, the person who last had his/her birthday and was eighteen years or above was selected for the interview. Non-Chinese households, commercial numbers, telephone numbers that were not answered after three attempts and households without any eligible subjects upon three contacts were excluded from the study. Subjects who could not communicate by telephone were also excluded.

\section{Sample}

A total of 7185 telephone numbers were attempted, 3957 telephone numbers were not answered after three attempts, there were no eligible subjects in 266 households, and 105 were commercial or invalid numbers. Two thousand eight hundred and fifty seven eligible households were contacted and 2512 subjects agreed to be surveyed but 
only 2410 completed the interview, giving a response rate of $84.4 \%$ (2410/2857). Table 1 compares the sociodemographic characteristics of the sample to that of the Hong Kong General Population 1996 By-census (Census \& Statistics Department Hong Kong 1996). The proportion of young adults was lower and that of the elderly was higher than those of the By-census. The distribution in occupation of our subjects was not directly comparable to that of the By-census, because different methods of classification of occupation were used. We used the British Registrar General's classification of occupation in order to indicate social class (General Registrar Office 1966), but the By-census used the International Standard Classification of Occupation.

\section{Survey Instrument and Outcome Measures}

The survey instrument consisted of a structured questionnaire on service utilisation rates, sociodemographic characteristics, chronic morbidity and the Chinese (HK) version of the SF-36 (Lam et al 1998). Service utilisation was measured by self-reported annual consultation rate (number of outpatient consultations with a registered medical practitioner in the past one year), monthly consultation rate (number of outpatient consultations with a registered medical practitioner in the past one month), and hospitalisation rate (any admission into the hospital in the past one year). Chronic morbidity was measured by the total number of known chronic diseases and the presence of a specific diagnosis. Each subject was asked if he/she had ever been diagnosed by a registered medical practitioner, for more than one month, to have hypertension, diabetes mellitus, heart disease of any kind, stroke, chronic lung disease (asthma or other chronic respiratory diseases), arthritis, mental 
illness or any other chronic disease. The total number of chronic diseases was calculated by the summation of the number of positive responses to the questions on the presence of each specific diagnosis and any other chronic disease. Demographic variables that were collected included age, gender, educational level, marital status and social class by occupation (General Registrar Office 1966).

The SF-36 was chosen as the measure of HRQOL because it is widely available and has been translated, validated and normed on our Chinese population (Lam et al 1998; Lam et al 1999). It has eight scales: physical functioning (PF), role limitation due to physical problems (RP), bodily pain (BP), general health (GH), vitality (VT), social functioning (SF), role limitation due to emotional problems (RE) and mental health (MH). Each scale has a score that ranges from zero to 100; a higher score indicates better HRQOL (Ware et al 1993).

\section{Data Analysis}

We hypothesized that sociodemographic factors, chronic morbidity and the SF36 scores were possible determinants of service utilisations. Annual consultation, monthly consultation and hospitalisation rates were used as separate dependent variables of service utilisation. The independent variables were grouped into three clusters: First, the sociodemographic variables including age (continuous), gender (1= male [reference level], $2=$ female), educational level ( $1=$ no formal schooling, $2=$ primary, $3=$ secondary, 4 = tertiary [reference level]), social class by occupation (1= professional [reference level], $2=$ associate professional, $3=$ skilled workers, $4=$ semiskilled workers, $5=$ non-skilled workers) and marital status (1=married [reference level], $2=$ others). Second, the chronic morbidity variables including the total number 
of chronic diseases (continuous) and each specific diagnosis (absent $=0$ [reference level], present=1). Third, the eight SF-36 scores (continuous). We expected a linear relationship between the SF-36 scores and service utilisation, as found by Hornbrook et al (Hornbrook and Goodman 1995; Hornbrook and Goodman 1996) because the SF-36 scores are continuous variables and there is no cut-off threshold for good or bad HRQOL.

We first entered all independent variables into a free forward stepwise regression model to determine the independent effect of each factor on each service utilisation rate. On the other hand, we hypothesised that clusters of variables may have a sequential causal relationship. Specifically, sociodemographic variables (cluster 1) can affect chronic morbidity (cluster 2) and SF-36 scores (cluster 3) as well as service utilisation. Similarly, chronic morbidity can affect SF-36 scores as well as service utilisation. As a result, simultaneous consideration of variables from the clusters in a free multiple regression model might result in confounded inference of sociodemographic and chronic morbidity variables. Therefore, we carried out a structured multiphase regression analysis, as that used by Cohen et al (Cohen et al 1999), in three phases: Phase 1 was a forward stepwise regression of service utilisation rates on cluster 1 variables; in phase 2, we forced into the model all variables selected in phase 1 before cluster 2 variables were entered by the same forward stepwise approach; the third phase was the entry of cluster 3 variables by the same regression method, after forcing into the model all the selected variables from phase 1 and 2. The proportion of variance in service utilisation rates that the SF-36 scores added to the other two clusters of variables was calculated from the difference in model R squares between the second and third phases of regressions. 
Our hypothesis on a sequential causal relationship between sociodemography, morbidity, HRQOL and service utilisation might be an over-simplified one, but the testing for more complex causal or interactive relationships is beyond the scope of this cross-sectional study.

Any departures from model assumptions were checked by examining deleted studentized residuals for multiple linear regression models or the Hosmer and Lemeshow goodness of fit test for logistic regression models (Hosmer and Lemeshow 2000).

Females tend to have higher service utilisation rates and lower HRQOL scores than men (Hulka and Wheat 1985; Hornbrook and Goodman 1995; Mulunpalo et al 1997; Nelson et al 1998; Lam et al 1999), we carried out the analysis for all subjects and by gender in order to see if there was any gender difference in the effects of HRQOL on service utilisation rates.

All data analyses were done by the SPSS-Windows 8.0 programme (SPSS Inc 1998). Variable entry and exclusion criteria for the forward stepwise regression models were p values of the F statistics of 0.05 and 0.10 , respectively. Subjects with unknown or missing data in any variable included in the model were excluded from the relevant regression analysis, resulting in different sample sizes in different regression models. 


\section{Results}

\section{Service Utilisation Rates}

The reported mean annual consultation rate was 3.73, the mean monthly consultation rate was 0.48 and $4.5 \%$ of subjects said that they had been hospitalised in the previous year. Five hundred and seventy nine (24\%) subjects had one and 338 (14 \%) had more than one chronic diseases, 1349 (56\%) subjects did not report any chronic disease and 144 (6\%) people were not sure whether they had any or not.

Table 2 compares the service utilisation rates of subjects with different number and type of chronic diseases. The unadjusted service utilisation rates of subjects with one or more chronic diseases were two to three times of those of people without. The utilisation rates tended to increase with the total number of chronic diseases.

\section{Determinants of Service Utilisation}

Table 3 shows the independent effects of sociodemographic variables , chronic morbidity and SF-36 scores on service utilisation by free forward stepwise multiple regressions. Five of eight SF-36 scores had a negative linear correlation with one or both annual and monthly consultation rates, which meant better HRQOL scores were associated with lower consultation rates. On the other hand, higher RE score was associated with a higher monthly consultation rate. The total number of chronic diseases was, but most specific diagnoses were not, a strong determinant of consultation rates. On the other hand, the presence of diabetes mellitus, chronic lung 
disease and stroke were stronger risk factors of hospitalisation than any of the SF-36 scores or the total number of chronic conditions.

Table 4 shows the structured multiphase regression model for annual consultation rate. Sociodemographic factors explained only 3.5\% of the variance, adding morbidity variables increased the proportion of variance explained to $14.1 \%$ and the final model with the inclusion of SF-36 scores explained $27.8 \%$ of the total variance for all subjects. The effect of SF score on annual consultation rates disappeared when the data were analysed by gender. PF score had an effect on the annual consultation rate for men but not for women, while the reverse was true for the RP score.

Table 5 shows the structured multiphase regression model for the monthly consultation rate. Sociodemographic and morbidity variables together explained only $7.8 \%$ of the total variance and the addition of the SF-36 scores significantly increased the proportion of variance explained to $20.7 \%$ for all subjects. The contradictory effect of RE score on the monthly consultation rate that was significant in the free regression model disappeared in the structured multiphase model. The effect of VT score became significant for women and that of PF score was significant for men when the data were analysed by gender.

Table 6 shows the structured multiphase regression model for hospitalisation rate in the last one year. The cluster of chronic morbidity variables contributed the greatest proportion of the variance explained, while the SF-36 scores added $4.6 \%$, 3.9\% and $8.5 \%$ more for all subjects, men and women, respectively. The estimated proportion of variance explained by the regression model was much higher for women than men. PF score had a significant effect but the BP score was excluded from the model for men when the data were analysed by gender. 
Scatter plots of annual or monthly consultation rates against the SF-36 scores showed linear correlations as hypothesised. Plots of deleted studentized results against predicted values and other independent variables for the final linear regression models were examined and no obvious model departures including non-linearity were observed. Goodness of fit test for the final logistic regression models did not show any substantial model inadequacies either. The corresponding p-values were 0.479 , 0.362 and 0.106 for the overall, male and female samples, respectively. 


\section{Discussion}

To the best of our knowledge, this was the first study to show a linear relationship between the SF-36 scores and health service utilisation in a general Chinese population. The effect of the SF-36 scores on consultation rates were stronger than those of sociodemographic and morbidity factors, as found by other studies in Western populations (Freeborn et al 1977; Kronenfeld 1978; Hulka and Wheat 1985; Hornbrook and Goodman 1996; Dunlop et al 2000). The absolute proportion of variance explained by the SF-36 scores were similar for annual and monthly consultation ( $13.7 \%$ and $13.0 \%)$, but it was relatively more significant for the monthly consultation rate because the proportion of variance in the latter explained by sociodemographic and chronic morbidity factors was smaller.

As shown by Hornbrook et al, the addition of the SF-36 scores to sociodemographic and chronic morbidity variables significantly increased the proportion of variance explained in service utilisation (Hornbrook and Goodman 1996). The SF-36 captures the variation in service utilisation resulting from a person's perceived need, which is independent of objective social and morbidity factors (Najman and Levine 1981; Li et al 1998; Andersen and Newman 1973; Browne et al 1990; Memel 1996).

Although HRQOL and chronic morbidity might be closely related in that the presence of a chronic disease might impair HRQOL and adverse HRQOL might predispose to chronic diseases especially psychological problems, we found that HRQOL (the SF-36 scores) and chronic morbidity were two independent determinants of service utilisation (Table 3). Andersen and Newman also classified evaluated illness level (morbidity) and perceived health status into two different 
factors in their taxonomy of determinants of medical care utilisation (Andersen and Newman 1973). Our results did not support Hornbrook and Goodman's view that the SF-36 scores could capture all the effect of chronic morbidity on service utilisation (Hornbrook and Goodman 1995). The use of one indicator that combines both concepts such as the limiting long-standing illness (LLI) used in the general household survey in the Untied Kingdom (Gould and Jones 1996) may under estimate the impact of either one of these needs-related factors on service utilisation (Cohen et al 1995; Sutton et al 1999) .

The effect of the SF-36 scores on hospitalisation rate was relatively small. Nelson et al also found that functional status explained only $1.2 \%$ of the total variance in the hospitalisation rate of patients with chronic diseases (Nelson et al 1998). Admission into the hospital, contrary to outpatient consultations, is usually determined by the doctor rather than the patient. It is more dependent on objective clinical indicators such as diagnosis and the severity of disease than the patient's perceived need (Wolinsky 1978; Hulka and Wheat 1985). Furthermore, the SF-36 is designed for the evaluation of ambulatory subjects, therefore may have a floor-effect for people who are seriously ill (Ware et al 1993). Other instruments that are designed for the measurement of low levels of functioning, e.g. the Barthel Index (Wade and Collin 1988), may be more suitable for the determination of the risk of hospitalisation. A large proportion of variance in hospitalisation rates was not explained by the factors examined in this study, more research is required to identify any other important determinants.

HRQOL measured by the SF-36 was an important determinant of service utilisation rates for both men and women although there was some gender difference in the relative significance of different domains. The most consistent gender 
difference was found with the PF score, which was a significant determinant of all utilisation rates for men but not for women. This could be explained by a gender difference in the actual and expected normal levels of physical functioning.

Sociodemographic variables, although commonly used as the major medicalrisk adjustment factors, explained only around three percents of the variance in any service utilisation rate. This was consistent with the results from other studies (Hornbrook and Goodman 1995; Hornbrook and Goodman 1996; Nelson et al 1998). Some studies have found a social gradient in service utilisation rates (Carr-Hill et al 1996; Buckingham and Freeman 1997; McNiece and Majeed 1999), but we found that social class did not have any independent effect on service utilisation, after controlling for chronic morbidity and HRQOL. Several other studies also found that the socioeconomic effect on service utilisation disappeared when health status was controlled for (Freeborn et al 1977; Hulka and Wheat 1985). Higher service utilisation rates observed among people in the working class are likely to be the result from higher morbidity rates (Gould and Jones 1996; Marmot et al 1997; Smith et al 1997) and poorer HRQOL (Borg and Kristensen 2000; Power et al 1988; Marmot and Wilkinson 2001) associated with socioeconomic disadvantages.

We used annual and monthly consultation rates and hospitalisation rate as indicators of service utilisation because they directly measure workload (Hulka and Wheat 1985; Nelson et al 1998; Dunlop et al 2000). They were analysed as separate dependent variables because they may not share the same set of determinants of utilisation and HRQOL may have different effects on different services, as found in our study. Theoretically, health care expense can be used as a summative indicator of all service utilisations but it is not applicable to Hong Kong because variations in payment methods and prices of health services are very big (The Harvard Team 
1999). We have not measured the use of traditional Chinese medicine (TCM) in our study because it formed a relatively small part of the overall health services and there was no agreed definition of TCM at the time of the study. The registration of TCM practitioners is underway and when it has been established it will be possible to study if the determinants of the utilisation of TCM are different from those of Western medicine.

Telephone interview was chosen as the method of survey in this study because it is applicable to the illiterate, who make up $10 \%$ of all adults and $39 \%$ of those aged 60 or above of the population in Hong Kong (Census \& Statistics Department Hong Kong 1996), and it is more cost-effective than face-to-face interviews (Marcus and Crane1986). Lam et al have shown that the results on doctor consultation rates found by telephone interviews were comparable to those of the face-to-face general household survey in Hong Kong (Lam et al 1988). A limitation of our survey method was that it excluded the very ill patients and those who were institutionalised, therefore, the results may not be applicable to these special groups. It also did not reach $10 \%$ of the households whose numbers were not listed in the telephone directories. This might be the cause of a relatively higher proportion of elderly subjects and working class people in our sample. This bias might have affected the reported utilisation rates but should not have much effect on the results of the regression analyses that were controlled for sociodemographic variables. Previous studies have shown that telephone interviews might lead to better SF-36 scores than self-completion (McHorney et al 1994), fortunately the bias is expected to be consistent for all subjects and should not affect our conclusions.

Self-reported utilisation rates are prone to recall errors. It has been found that $5 \%$ of subjects over-reported their outpatient consultation rates for the four months 
closest to the survey date and $25 \%$ under-reported consultations that they had 5 to 6 months ago (Nelson et al 1998). This explained why the reported mean annual consultation rate (3.73) was lower than that (5.76) projected from the monthly consultation rate in this study. As pointed out by Nelson et al, self-reported rates should not be taken as the actual consultation rates but only an indication of the utilisation pattern. We expected such errors to be random and not to have any effect on the results of the regression analyses in this study.

The measure of chronic morbidity by subjects' recall of doctor's diagnosis could inflate the correlation between chronic diseases and utilisation rate because the presence of a diagnosis depended upon a prior consultation and service utilisation might increase the likelihood of reporting an illness (Sutton et al 1999). We tried to reduce such a bias by including only chronic diseases that had been diagnosed by a registered doctor for at least four weeks and testing the effect of chronic morbidity on both annual and monthly consultation rates.

The causal relationship between socio-economic status, chronic morbidity, HRQOL and service utilisation can be reversed or bi-directional. The presence of a chronic disease could lead to a drop in social status; service utilisation might increase the diagnosis of chronic diseases and/or change HRQOL perception; poor HRQOL and psychological problems may aggravate one another. More comprehensive longitudinal studies will be required to sort out these complex causal relationships. 


\section{Conclusions}

HRQOL measured by the SF-36 was a more important determinant of outpatient consultation rates than chronic morbidity and sociodemographic factors. The addition of the SF-36 scores almost doubled the proportion of variance explained for annual consultation rate and tripled that for monthly consultation rate. To a lesser extent, the SF-36 scores also affected the risk of hospitalisation. HRQOL data can supplement sociodemographic and chronic morbidity factors in the estimation of health service needs. Interventions that aim at improving the HRQOL of patients may reduce the demand for health care services.

The results of our study supported the clinical relevance of the SF-36 to a culture and health care system that is very different from that of the United States where the instrument originated. They provided evidence on the clinical significance of HRQOL for the Chinese, which is the largest ethnic group in Asia and the world. HRQOL has now been found to be an important determinant of health service utilisation for both the Chinese and the Japanese, it is very likely that the same will be found for other Asian populations.

We cannot draw a firm conclusion on the predictive relationship between the SF-36 scores and service utilisation rates from this cross-sectional study although the results were suggestive. Further prospective studies will be required to confirm our hypothesis and to test for the presence of any reverse causal relationship between social status, chronic morbidity, HRQOL and service utilisation. 


\section{Acknowledgements}

This study was funded by a research grant (HSRC \# 711026) from the Health Services Research Committee, the Government of the Hong Kong SAR. We would like to thank Ms. Barbara Gandek, Director, IQOLA Project, for her advice on this research project. Thanks also go to Mr. Alex Chan, Senior Research Assistant, for his assistance in data collection and analysis.

\section{Ethics Approval}

This research project was approved by the Ethics Committee, Faculty of Medicine, the University of Hong Kong. 


\section{References}

Abbasi K. (1999) The World Bank and world health: Healthcare strategy. British Medical Journal 318: 933-936.

Andersen R. and Newman J.F. (1973) Societal and individual determinants of medical care utilization in the United States. The Milbank Memorial Fund Quarterly 50: 95124.

Borg V. and Kristensen T.S. (2000) Social class and self-rated health: can the gradient be explained by differences in life style or work environment? Social Science and Medicine 51: 1019-1030.

Browne G.B., Arpin K., Corey P., Fitch M. and Gafni A. (1990) Individual correlates of health service utilization and the cost of poor adjustment to chronic illness. Medical Care 28: 43-58.

Buckingham K. and Freeman P. (1997) Sociodemographic and morbidity indicators of need in relation to the use of community health services: observational study. British Medical Journal 315: 994-996.

Carr-Hill R.A., Rice N. and Roland M. (1996) Socioeconomic determinants of rates of consultation in general practice based on fourth national morbidity survey of general practices. British Medical Journal 312: 1008-1013. 
Census \& Statistics Department Hong Kong. (1996) 1996 Population By-census Summary Results. Government Printer, Hong Kong.

Cheng Y.H, Chi I., Boey K.W. and Ko L.S.F. (1997) An exploratory study on utilisation pattern and costs of aged care in Hong Kong: implications for formal care in the community. Journal of the Hong Kong Geriatric Society 8: 16-23.

Cohen G., Forbes J. and Garraway M. (1995) Interpreting self-reported limiting long term illness. British Medical Journal 311: 722-724.

Cohen Y.C., Robin H., Freedman L. and Mozes B. (1999) Use of a clustered model to identify factors affecting hospital length of stay. Journal of Clinical Epidemiology 52: 1031-1036.

Dunlop S., Coyte P.C. and McIsaac W. (2000) Socio-economic status and the utilisation of physicians' services: results from the Canadian National Population Health Survey. Social Science \& Medicine 51: 123-133.

Freeborn D.K., Pope C.R., Davis M.A. and Mullooly J.P. (1977) Health status, socioeconomic status, and utilization of outpatient services for members of a prepaid group practice. Medical Care 15: 115-128.

General Registrar Office. (1966) Registrar General's Classification of Occupation, HMSO, London. 
Gould M.I. and Jones K. (1996) Analysing perceived limiting long-term illness using U.K. census microdata. Social Science \& Medicine 42: 857-869.

Hongkong Telecom. (1997) Residential Telephone Directories- Hong Kong \& Islands, Kowloon and New Territories. Hongkong Telecom, Hong Kong.

Hornbrook M.C. and Goodman M.J. (1995) Assessing relative health plan risk with the RAND-36 Health Survey. Inquiry 32: 56-74.

Hornbrook M.C. and Goodman M.J. (1996) Chronic disease, functional health status, and demographics: a multi-dimensional approach to risk adjustment. Health Services Research 31: 283-307.

Hosmer DW, Jr and Lemeshow S. (2000) Applied logistic regression. Wiley: New York.

Hulka B.S. and Wheat J.R. (1985) Patterns of utilization- the patient perspective. Medical Care 23: 438-460.

Kronenfeld J.J. (1978) Provider variables and the utilization of ambulatory care services. Journal of Health \& Social Behavior:19: 68-76. 
Lam C.L.K, Gandek B, Ren X.S. and Chan M.S. (1998) Tests of scaling assumptions and construct validity of the Chinese (HK) version of the SF-36 Health Survey. Journal of Clinical Epidemiology 51: 1139-1147.

Lam C.L.K, Lauder I.J., Lam T.P. and Gandek B. (1999) Population based norming of the Chinese(HK) version of the SF-36 health survey. Hong Kong Practitioner 21: 460-470.

Lam T.H, Kleevans J. W.L. and Wong C.M. (1988) Doctor-consultation in Hong Kong: a comparison between findings of a telephone interview with general household survey. Community Medicine 10: 175-179.

Li L., Young D., Wei H., Zhang Y. and Zheng Y. (1998) The relationship between objective life status and subjective life satisfaction with quality of life. Behavioral Medicine 23: 149-159.

Marcus A.C. and Crane L.A. (1986) Telephone surveys in public health research. Medical Care 24: 97-112.

Marmot M., Ryff C.D., Bumpass L.L., Shipley M. and Marks N.F. (1997) Social inequalities in health: next questions and converging evidence. Social Science \& Medicine 44: 901-910. 
Marmot M., Wilkinson R.G. (2001) Psychosocial and marital pathways in the relation between income and health: a response to Lynch et al. British Medical Journal 322: 1233-1236.

Matsumura S. (2000). Perceived health status as a predictor of utilization of healthcare resources and the number of sick-leave days in Japan. Quality of Life Research 9: 1063.

McHorney C.A., Kosinski M. and Ware J.E. (1994) Comparisons of the costs and quality of norms for the SF-36 health survey collected by mail versus telephone interview: results from a national survey. Medical Care 32: 551-567.

McNiece R. and Majeed A. (1999) Socioeconomic differences in general practice consultation rates in patients aged 65 and over: prospective cohort study. British Medical Journal 319: 26-28.

Memel D. (1996) Chronic disease or physical disability? The role of the general practitioner. British Journal of General Practice 46: 109-113.

Mulunpalo S., Vuori I., Oja P., Pasanen M. and Urponen H. (1997) Self-rated health status as a health measure: the predictive value of self-reported health status on the use of physician services and on mortality in the working-age population. Journal of Clinical Epidemiology 50: 517-528. 
Nagelkerke N.J.D. (1991) A note on a general definition of the coefficient of determination. Biometrika 78: 691-692.

Najman J.M. and Levine S. (1981) Evaluating the impact of medical care and technologies on the quality of life: a review and critique. Social Science \& Medicine 15F: 107-115.

Nelson E.C., McHorney C.A, Manning W.G., Rogers W.H., Zubkoff M., Greenfield S., Ware J.E. and Tarlov A.R. (1998) A longitudinal study of hospitalisation rates for patients with chronic disease: results from the Medical Outcomes Study. Health Services Research 32: 759-774.

Power C., Matthews S. and Manor O. (1988) Inequalities in self-rated health: explanations from different stages of life. Lancet 351: 1009-1014.

Smith G.D., Hart C., Blane D., Gills C. and Hawthorne V. (1997) Lifetime socioeconomic position and mortality: prospective observational study. British Medical Journal 314: 547-552.

SPSS Inc. (1998) SPSS Base 8.0 User's Guide. SPSS Inc., Chicago.

Sutton M., Carr-Hill R., Gravelle H. and Rice N. (1999) Do measures of self-reported morbidity bias the estimation of the determinants of health care utilisation? Social Science \& Medicine 49: 867-878. 
Testa M.A. and Simonson D.C. (1996) Assessment of quality-of-life outcomes. New

England Journal of Medicine 334: 835-840.

The Harvard Team. (1999) Improving Hong Kong's Health Care System: Why and for Whom. Hong Kong SAR :Government Printing Department.

Wade D.T., and Collin C. (1988) The Barthel ADL Index: a standard measure of physical disability? International Disability Studies 10: 64-67.

Ware J.E., Snow K.K., Kosinski M. and Gandek B. (1993) The SF-36 Health SurveyManual and Interpretation Guide. Boston, MA : The Health Institute,

Deleted: Boston, MA

Wolinsky F.D. (1978) Assessing the effects of predisposing, enabling, and illnessmorbidity characteristics on health service utilization. Journal of Health \& Social Behavior 19: 384-396. 
Table 1: Sociodemographic Characteristics of Study Sample Compared to the Hong Kong General Population By-census

\begin{tabular}{|c|c|c|c|}
\hline & $\begin{array}{l}\text { Sample } \\
\mathrm{N}=\mathbf{2 4 1 0}\end{array}$ & $\begin{array}{l}\text { Hong Kong Adults } 18+\text { years } \\
\qquad \mathrm{N}=4,811,510\end{array}$ \\
\hline \multicolumn{2}{|c|}{ Mean Age } & 42.9 (SD 17.73) years & 42.3 years \\
\hline \multicolumn{4}{|c|}{ Age Group (years) } \\
\hline \multicolumn{2}{|c|}{$18-44$} & $56.7 \%$ & $62.0 \%$ \\
\hline \multicolumn{2}{|c|}{$45-64$} & $23.7 \%$ & $24.9 \%$ \\
\hline \multicolumn{2}{|c|}{65 or above } & $15.3 \%$ & $13.1 \%$ \\
\hline \multicolumn{2}{|c|}{ Refused to answer } & $4.2 \%$ & $0 \%$ \\
\hline \multicolumn{2}{|c|}{ Male } & $47.8 \%$ & $49.5 \%$ \\
\hline \multicolumn{2}{|c|}{ Female } & $52.2 \%$ & $50.5 \%$ \\
\hline \multicolumn{4}{|c|}{ Marital Status } \\
\hline a) & Now Married & $58.0 \%$ & $60.6 \%$ \\
\hline b) & Never Married & $33.8 \%$ & $31.5 \%$ \\
\hline c) & Widowed & $5.8 \%$ & $5.9 \%$ \\
\hline d) & Divorced/Separated & $1.3 \%$ & $1.9 \%$ \\
\hline e) & Refused to Answer & $1.1 \%$ & $0 \%$ \\
\hline \multicolumn{4}{|c|}{ Educational Level } \\
\hline a) & No Schooling & $6.9 \%$ & $9.5 \%$ \\
\hline b) & Primary & $22.3 \%$ & $22.6 \%$ \\
\hline c) & Secondary & $52.2 \%$ & $52.7 \%$ \\
\hline & Tertiary & $17.8 \%$ & $15.2 \%$ \\
\hline e) & Refused to Answer & $0.9 \%$ & $0 \%$ \\
\hline \multicolumn{4}{|c|}{ Social Class by Occupation } \\
\hline a) & Professional & $3.1 \%$ & $9.4 \%^{\mathrm{a}}$ \\
\hline b) & Associate Professional & $14.7 \%$ & $19.9 \%^{\mathrm{b}}$ \\
\hline c) & Skilled Worker & $35.4 \%$ & $37.6 \%^{c}$ \\
\hline d) & Semi-skilled Worker & $24.6 \%$ & $13.8 \%{ }^{\mathrm{d}}$ \\
\hline e) & Non-skilled Worker & $13.4 \%$ & $18.6 \%^{\mathrm{e}}$ \\
\hline f) & Unclassified & $1.0 \%$ & $0.7 \%$ \\
\hline g) & Refused to Answer & $7.7 \%$ & $0 \%$ \\
\hline
\end{tabular}

\section{$\underline{\text { Notes }}$}

a. This includes professionals, diplomats, Government administrators and corporate managers.

b. This includes all associate professionals and small company managers.

c. This includes clerks, craft workers, plant and machine operators and assemblers.

d. This includes service and shop sales workers.

e. $\quad$ This includes all workers in elementary occupations.

Percentages may not add up to $100 \%$ because of rounding. 
Table 2: Distribution of Service Utilisation Rates by the Number and Type of Chronic Diseases

\begin{tabular}{|c|c|c|c|}
\hline & \multicolumn{2}{|c|}{ Mean Number of Consultations (95\% CI) } & \multirow{2}{*}{$\begin{array}{l}\text { Proportion of persons } \\
\text { Hospitalised Last Year }\end{array}$} \\
\hline & Last Year & Last Month & \\
\hline $\begin{array}{l}\text { Total Sample } \\
(\mathrm{n}=2410)\end{array}$ & $3.73(3.54,3.92)$ & $0.48(0.43,0.52)$ & $4.5 \%$ \\
\hline $\begin{array}{l}\text { No Chronic Disease } \\
\quad(n=1349)\end{array}$ & $2.75(2.56,2.93)$ & $0.27(0.23,0.31)$ & $2.2 \%$ \\
\hline$\geq \underset{(n=917)}{1 \text { Chronic Disease }}$ & $5.47(5.08,5.86)$ & $0.81(0.71,0.91)$ & $7.7 \%$ \\
\hline
\end{tabular}

Total Number of Chronic Disease

$\begin{array}{llll}\text { One }(\mathrm{n}=579) & 4.82(4.35,5.29) & 0.66(0.55,0.77) & 5.9 \% \\ \text { Two }(\mathrm{n}=226) & 5.43(4.82,6.04) & 0.82(0.62,1.01) & 8.8 \% \\ \text { Three }(\mathrm{n}=79) & 8.9(7.25,10.71) & 1.34(0.86,1.81) & 8.9 \% \\ \text { Four }(\mathrm{n}=20) & 9.81(6.87,12.75) & 2.40(1.05,3.75) & 25.0 \% \\ \text { Five }(\mathrm{n}=10) & 10.50(-0.5,21.50) & 1.50(0.32,2.68) & 40.0 \% \\ \text { Six }(\mathrm{n}=3) & 14.00(-113.1,141.1) & 1.00(-11.71,13.71) & 33.3 \%^{\#}\end{array}$

Specific Diagnosis

\begin{tabular}{llll} 
HT $(\mathrm{n}=271)$ & $6.68(5.90,7.47)$ & $0.81(0.65,0.98)$ & $9.6 \%$ \\
DM $(\mathrm{n}=110)$ & $6.95(5.83,8.07)$ & $0.97(0.73,1.21)$ & $7.3 \%$ \\
Heart $(\mathrm{n}=94)$ & $7.10(5.64,8.56)$ & $1.36(0.96,1.75)$ & $17.0 \%$ \\
Lung $(\mathrm{n}=127)$ & $6.04(5.03,7.04)$ & $0.88(0.64,1.12)$ & $14.2 \%$ \\
Stroke $(\mathrm{n}=21)$ & $7.18(4.38,9.97)$ & $0.89(0.44,1.35)$ & $33.3 \%$ \\
Arthritis $(\mathrm{n}=472)$ & $5.21(4.70,5.73)$ & $0.91(0.74,1.07)$ & $6.1 \%$ \\
Mental $(\mathrm{n}=94)$ & $6.69(5.15,8.23)$ & $1.30(0.78,1.82)$ & $8.5 \%$ \\
Others $(\mathrm{n}=225)$ & $6.81(5.80,7.82)$ & $0.95(0.71,1.18)$ & $8.0 \%$ \\
\hline
\end{tabular}

\section{$\underline{\text { Statistical Notes }}$}

1. The difference in proportions between each disease group and the 'no chronic disease' group was statistically significant ( $p<0.0001, d f=1$, Chi square test), except for the group marked with \# ( $p=0.06$, Fisher's Exact Test). 
Table 3: Multivariate Regression Model Explaining Service Utilisation Rates by Sociodemographic Characteristics, Chronic Morbidity and SF-36 Scores

Annual Consultation Rate $(\mathrm{N}=1904)$

${ }^{\text {a }}$ Coefficients $\quad{ }^{b}$ Beta

Sociodemographic Characteristics

\section{Gender \\ 0.526 \\ Marital Status \\ Social Class \\ Education \\ Chronic Morbidity}

$-0.016$

$-0.061$

Total number $\quad 0.66$

0.131

Monthly Consultation Rate

$(\mathrm{N}=2107)$

Hospitalisation Rate

$(\mathrm{N}=2119)$

${ }^{a}$ Coefficients $\quad{ }^{\mathbf{b}}$ Beta

'Odds Ratio (95\%CI)

$\begin{array}{lllllc}\text { HT } & 1.412 & 0.096 & --- & --- & ---- \\ \text { DM } & ---- & --- & --- & --- & 2.809(1.450,5.443) \\ \text { Heart } & \text { NS } & \text { NS } & ---- & --- & --- \\ \text { Lung } & --- & --- & --- & --- & 2.271(1.199,4.301) \\ \text { Stroke } & --- & --- & --- & --- & 5.950(1.941,18.241) \\ \text { Arthritis } & -0.939 & -0.081 & ---- & ---- & ---- \\ \text { Mental } & --- & --- & --- & --- & ---\end{array}$

\section{$\underline{\text { SF-36 Scores }}$}

\begin{tabular}{lccccc} 
PF & -0.045 & -0.120 & --- & ---- & ---- \\
RP & -0.009 & -0.060 & -0.009 & -0.244 & $0.989(0.982,0.995)$ \\
BP & -0.039 & -0.187 & -0.008 & -0.156 & $0.989(0.980,0.998)$ \\
GH & -0.039 & -0.173 & -0.008 & -0.139 & ---- \\
VT & --- & --- & ---- & --- & --- \\
SF & -0.012 & -0.043 & --- & --- & --- \\
RE & ---- & --- & 0.001 & 0.043 & --- \\
MH & --- & ---- & --- & --- & -1.713 \\
\hline \multirow{2}{*}{ Constant } & 14.866 & & 2.053 & & 0.124 \\
& & & & &
\end{tabular}

\section{$\underline{\text { Statistical Notes }}$}

a. Unstandardised regression coefficients of variables that were included in the model with $p$ values $<0.05$

$b$. Beta is the standardised regression coefficient, indicating the change in standard units of the dependent variable for each increase of one standard unit in the independent variable, controlling for all other independent variables.

c. The odds ratio of variables that were included in the model with $p$ values $<0.05$.

$d$. R square is the proportion of variance in the dependent variable explained by the independent variables included in the regression model. The $R$ square for hospitalisation rate was computed from Nagelkerke 'Pseudo' R square (Nagelkerke 1991)

NS means the variable was included in the model but $p$ was $>0.05$. 
Table 4: Structured Multiphase Regression Model for Annual Consultation Rate All Subjects ( $N=2050)$

\section{${ }^{\mathrm{a}} \mathrm{Co}$}

\section{Phase 1}

Age

Gender

Marital Status

$$
0.037
$$

$$
1.218
$$$$
0.561
$$

(0.025, 0.050)

$(0.839,1.598)$

$(0.126,0.996)$

0.145

0.137

0.062

0.013

0.019

0.003

0.013

0.032

0.035

$<0.001$

Phase 2

Total number

Arthritis

1.898

$-0.955$

0.750

(1.584, 2.213)

$(-1.579,-0.330)$

0.377

$-0.083$

0.059

0.013

0.094

0.107

0.141

$<0.001$

Phase 3

$\mathrm{PF}$

RP

BP

GH

SF

\section{$-0.045$}

$-0.010$

$-0.043$

$-0.037$

$-0.012$

$(-0.064,-0.026)$

$(-0.017,-0.003)$

$(-0.052,-0.033)$

$(-0.047,-0.027)$

$(-0.023,0.000)$
$-0.118$

$-0.065$

$-0.202$

$-0.162$

$-0.042$
0.034

$0.193<0.001$

$0.197 \quad 0.006$

$0.255<0.001$

$0.277<0.001$

$0.278 \quad 0.045$

\section{$\underline{\text { Males }((N=1050)}$}

\section{Phase 1}

Age

0.028

(0.014, 0.041)

0.129

0.023

0.023

$<0.001$

Phase 2

Total number

1.681

(1.394, 1.967 )

0.364

0.109

$0.132<0.001$

Phase 3

PF

BP

GH

$-0.088$

$-0.028$

$-0.028$

$(-0.113,-0.063)$

$(-0.040,-0.016)$

$-0.227$

0.076

$-0.136$

$(-0.04,-0.016)$

0.024

0.015

$0.208<0.001$

$0.232<0.001$

$0.247<0.001$

\section{Females $(N=1000)$}

\section{Phase 1}

Age

Marital Status

0.039

$(0.018,0.060)$

(0.421, 1.829)

0.131

0.008

0.008

$\begin{array}{lll}0.008 & 0.008 & <0.001 \\ 0.010 & 0.018 & 0.002\end{array}$

Phase 2

Total number

HT

1.214

1.594

$(0.763,1.665)$

0.112

Others

2.580

$(0.478,2.709)$

0.229

0.099

0.117

$<0.001$

(1.463, 3.697)

0.105

0.002

$0.119 \quad 0.005$

Phase 3

RP

$-0.020$

$(-0.030,-0.010)$

$0.137<0.001$

GH

$-0.055$

$-0.052$

$(-0.069,-0.041)$

$-0.129$

$-0.257$

0.075

0.062

$0.212<0.001$

$(-0.067,-0.036) \quad-0.211$

0.030

$0.274<0.001$

$0.304<0.001$

Statistical Notes

a. Unstandardised regression coefficients of variables that were included in the model with $p$ values $<0.05$.

$b$. Beta is the standardised regression coefficient, indicating the change in standard units of the dependent variable for each increase of one standard unit in the independent variable, controlling for all other independent variables.

c. $\quad$ Partial $R$ square is the proportion of variance in the dependent variable explained by each independent

variable.

d. $\quad R$ square is the proportion of variance in the dependent variable explained by the independent variables included in the regression model up to the relevant step. 
Table 5: Structured Multiphase Regression Model for Monthly Consultation Rate

$\begin{array}{llllll}{ }^{\mathrm{a}} \text { Coefficient } & 95 \% \mathrm{CI} & { }^{\mathrm{b}} \text { Beta } & { }^{\mathrm{c}} \text { Partial } \mathbf{R}^{2} & { }^{\mathrm{d}} \mathbf{R}^{2} & \mathbf{p}\end{array}$

\section{All Subjects $(\mathrm{N}=\mathbf{2 2 8 8})$}

$\begin{array}{lllllll}\begin{array}{l}\text { Phase 1 } \\ \text { Age } \\ \text { Gender }\end{array} & 0.009 & (0.006,0.012) & 0.138 & 0.020 & 0.020 & <0.001 \\ & 0.224 & (0.130,0.319) & 0.096 & 0.009 & 0.029 & <0.001 \\ \begin{array}{l}\text { Phase 2 } \\ \text { Total number }\end{array} & 0.358 & (0.292,0.423) & 0.279 & 0.046 & 0.076 & <0.001 \\ \text { HT } & -0.309 & (-0.491,-0.128) & -0.083 & 0.002 & 0.078 & 0.001 \\ & & & & & & \\ \text { Phase 3 } & & & & & & \\ \text { RP } & -0.008 & (-0.010,-0.006) & -0.214 & 0.092 & 0.170 & <0.001 \\ \text { BP } & -0.009 & (-0.011,-0.006) & -0.163 & 0.026 & 0.196 & <0.001 \\ \text { GH } & -0.008 & (-0.010,-0.005) & -0.130 & 0.012 & 0.207 & <0.001\end{array}$

\section{$\underline{\text { Males }(N=1119)}$}

\section{Phase 1}

Age

0.007

$(0.004,0.010)$

0.144

0.021

0.021

$<0.001$

Phase 2

Total number

HT

0.241

$(0.157,0.325)$

0.227

0.033

0.007

$0.054<0.001$

Mental

0.345

$(0.011,0.680)$

0.064

0.004

0.065

Phase 3

PF -0.001

$-0.001$

$(-0.017,-0.005)$

$-0.129$

$(-0.009,-0.006)$

$-0.235$

$(-0.010,-0.004) \quad-0.151$

0.069

0.078

BP

$-0.005$

$(-0.008,-0.002)$

$-0.101$

0.022

$0.134<0.001$

$0.212<0.001$

$0.007-0.241-0.001$

\section{Females ( $N=1169)$}

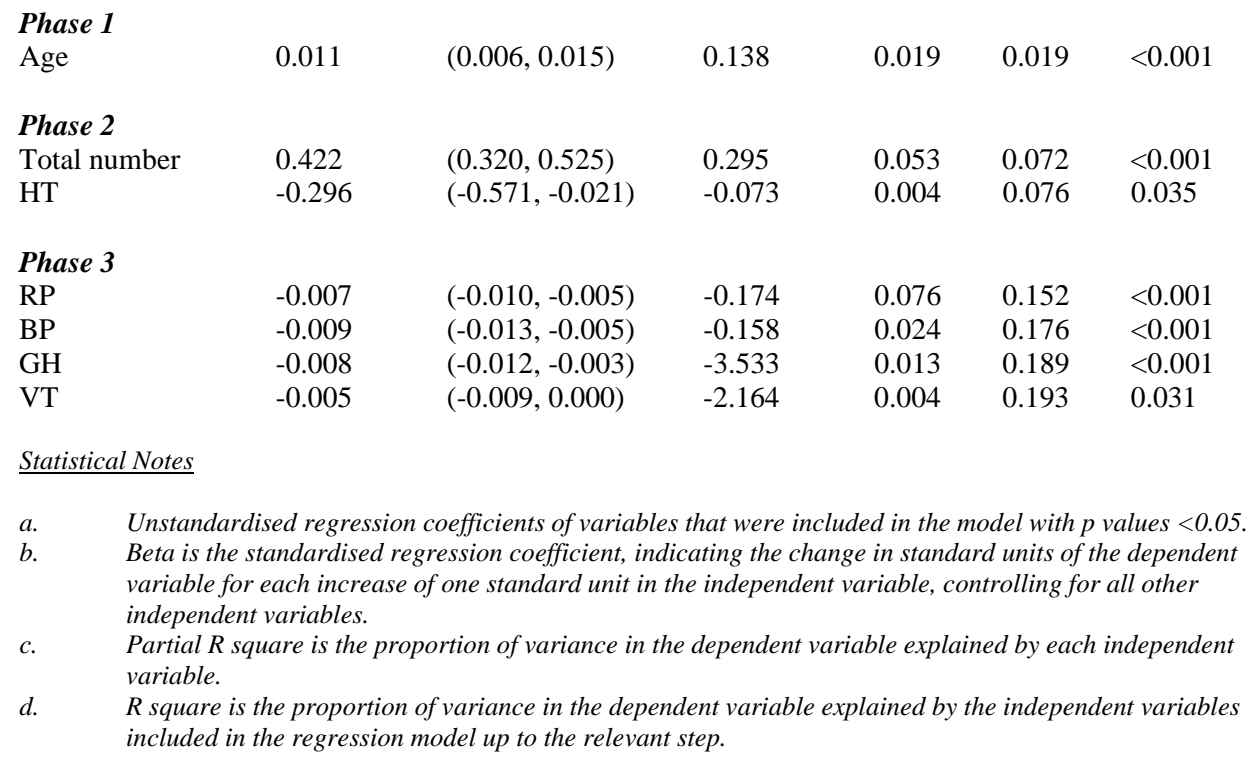


Table 6: Structured Multiphase Regression Model for Hospitalisation Rate

All Subjects ( $\mathrm{N}=\mathbf{2 3 3 1})$

Phase $1\left({ }^{a} R^{2}=0.025\right)$

Age

Marital Status

Phase $2\left({ }^{a} R^{2}=0.085\right)$

Total number

DM

Lung

Phase $3\left({ }^{a} R^{2}=0.131\right)$

$\mathrm{RP}$

BP

Males $(\mathrm{N}=1149)$

Phase $1\left({ }^{a} R^{2}=0\right)$

Phase $2\left({ }^{a} R^{2}=0.050\right)$

Total number

Lung

Phase $3\left({ }^{a} R^{2}=0.089\right)$

$\mathrm{PF}$

RP

Females. $(\mathrm{N}=1182)$

Phase $1\left({ }^{a} R^{2}=0.026\right)$

Age

1.024

$(1.008,1.04)$

0.002

Phase $2\left({ }^{a} R^{2}=0.123\right)$

Total number

Arthritis

Phase $3\left({ }^{a} R^{2}=0.208\right)$

RP

BP

0.982

1.022

1.815

$(1.012,1.033) \quad<0.001$

$(1.197,2.753) \quad 0.005$

1.461

2.255

(1.178, 1.813) $\quad 0.001$

$(1.132,4.492) \quad 0.021$

$(1.239,4.522) \quad 0.009$

$0.991 \quad(0.984,0.997) \quad 0.003$

0.986

$(0.977,0.995)$

0.002

1.464

$1.148,1.868) \quad 0.002$

$(1.112,5.540) \quad 0.027$

$\begin{array}{lll}0.979 & (0.960,0.997) & 0.027\end{array}$

$\begin{array}{lll}0.990 & (0.982,0.998) & 0.018\end{array}$

$95 \%$ CI

p

Statistical Notes

a. The R square for Hospitalisation rate was computed from Nagelkerke 'Pseudo' R square (Nagelkerke 1991) 